\title{
Fertilization with different soil types in viticulture: a three-year experience in Trentino Alto Adige
}

\author{
Stefano Pedò ${ }^{1 *}$, Daniela Bona $^{1}$, Andrea Cristoforetti ${ }^{1}$, Marco Ippolito ${ }^{1}$, Duilio Porro ${ }^{1}$ and Diego Trainotti ${ }^{2}$ \\ ${ }^{1}$ Technology Transfer Centre, Edmund Mach Foundation, Via E. Mach, 1 - 38010 San Michele all'Adige (TN), Italy \\ ${ }^{2}$ CAVIT s.c. Via del Ponte, 31 - 38123 Trento - Italy
}

\begin{abstract}
The work aimed at investigating the impact of various good quality soils of on vineyard productivity. Manure matured with a fast and controlled process and compost obtained from digestate of an organic fraction of municipal solid waste (OFMSW) were applied one time on a grapevine row, in two CAVIT vineyards. A physico-chemical characterization of the soils was carried out and biological quality indices QBS-ar (Arthropodological Biocenosis) were calculated. The vegeto-productive monitoring was performed by foliar nutrients analysis and measuring NDVI and SPAD indices. The organic source had a significant fertilizing effect, especially manure, which determined a nutrient increase in soil $(\mathrm{P}, \mathrm{K}$ and $\mathrm{Mg}$ ), a rise in photosynthetically active biomass, available nitrogen and potassium in plants. The effects on the biological community of soils and musts quality were negligible. The use of soil improvers could be an efficient strategy for the nutrition of not vigorous vineyards, which do not require high nitrogen inputs.
\end{abstract}

\section{Introduction}

In Trentino's vineyards, the quantity of organic matter in the soils is slowly decreasing. According to a research carried out at FEM, over a period of 30 years, from 1980 to 2011 , the average content of organic matter in 63 soils went from 3.2 to $2.6 \%$ [1].

In recent years, the availability of soil improvers has been growing in the province of Trento. The first soil improver considered in this work was the compost obtained from the aerobic treatment of digestate produced by dry anaerobic digestion of about 40,000 tons of OFMSW and 14,000 tons of green waste used as bulking agent, collected in the province. The second was some locally produced matured manure, which, after being mixed with straw, was treated for 90 days in a turned pile. These products can represent good quality fertilizers for vineyards: if used together with other techniques, they allow for a reduction in the use of synthetic fertilizers.

The aim of this work was to evaluate the use of two soil improvers in an open-field trial across several years and compare it with conventional fertility management.

\section{Materials and methods}

The experiments were carried out in two vineyards made available by CAVIT, an important wine cooperative located in Trentino. The fields were subdivided into three completely randomized blocks and fertilised with compost, manure and control (standard farm fertilization). The surface of each unit area was variable, but it covered at least $2,500 \mathrm{~m}^{2}$.
Soil improvers were applied during autumn 2015 (tables 1 and 2) and over the following years (2016-18) the main chemical parameters, soil biodiversity as well as vegetative, nutritional and production characteristics of vines accurately monitored.

The soil samples required for chemical characterization were collected in autumn 2015, right before the addition of soil improvers and yearly in the following three years. The following chemical-physical parameters were analyzed: texture (in 2015 and 2017), $\mathrm{pH}$, total limestone, active limestone, soil organic matter $(\mathrm{SOM})$, total nitrogen $(\mathrm{N})$, available phosphorus $(\mathrm{P})$, exchangeable potassium $(\mathrm{K})$, exchangeable magnesium, cation exchange capacity, $\mathrm{C} / \mathrm{N}$ ratio.

Table 1. Analytical characteristics of soil improvers

\begin{tabular}{|l|c|c|}
\hline & Compost & Manure \\
\hline Humidity (\% t.q.) & 32.0 & 72.9 \\
\hline pH & 8.8 & 8.4 \\
\hline EC (mS/cm) & 2800 & 1080 \\
\hline C org (\% dw) & 20.6 & 29.8 \\
\hline SOM (\%) & 3.6 & 5.1 \\
\hline C/N & 11.3 & 10.9 \\
\hline N tot. (\% dw) & 1.82 & 2.72 \\
\hline P tot. (\% dw) & 0.33 & 1.49 \\
\hline K tot. (\% dw) & 1.89 & 6.26 \\
\hline
\end{tabular}

\footnotetext{
* Corresponding author: $\underline{\text { stefano.pedo@fmach.it }}$
} 
Table 2. Quantities of soil improvers applied

\begin{tabular}{|l|c|c|}
\hline & Compost & Manure \\
\hline Quantity/he & $200 \mathrm{q}$ & $400 \mathrm{q}$ \\
\hline Dry matter (t) & 13.6 & 10.8 \\
\hline SOM (t) & 4.83 & 5.54 \\
\hline N (kg) & 247 & 294 \\
\hline P (kg) & 45 & 160 \\
\hline K (kg) & 257 & 676 \\
\hline
\end{tabular}

The biological tests, i.e. the soil biological quality index based on micro-arthropods (QBS-ar), were carried out in late summer/early autumn [2, 3]. The QBS-ar index is a tool for evaluating the qualitative status of communities of arthropods in the hypogeum environment. It gives increasing scores for ascertained quality levels. Alongside this index, other data were collected which they account for the richness and complex vitality of telluric organisms:

- Coenoses (demographic presences of detectable arthropods per $\left.\mathrm{m}^{2}\right)$;

- Quality Classes (obtained from harmonization of QBS-ar values with the verification of the presence of some key taxonomic groups);

- QBS-MAX (it represents the overall biodiversity detectable in the blocks and is obtained from harmonization of its replicas in the respective years);

- Number of taxa (number of taxonomic groups found in the soil);

- $\quad \mathrm{J}$ and $\mathrm{H}^{\prime}$ indices $[4,5]$ (ecological indices that take into account the balance between the populations and the number of taxonomic groups present on the total reachable);

- Percentage of sites with acari/collembola ratio [6] greater than 1 (in natural contexts this ratio is typically greater than 1 , therefore the percentage of sites that meet this condition was reported).

In order to study the effect of different fertilisation regimes on the grapevines, the soil parameters were correlated with the vegetative and nutritional state of the plants, assessed in the spring-summer period. Every year, non-destructive indices SPAD (SPAD-502 Plus, Konica Minolta) and NDVI (Greenseeker Handheld ${ }^{\circledR}$, Trimble Inc.) were calculated in two periods: at bunch closure and post-veraison (BBCH 77 and 85). The SPAD index measures the green colour intensity of the leaves and is used as an indirect estimation of the chlorophyll content. It was measured on 4 replicates of 15 vines/plot.

The NDVI index - an indicator of the photosynthetically active biomass - summarizes color and quantity of vegetation. It was measured on all of the plants of the different blocks under comparison (the index ranges between -1 and +1 , in the presence of vegetation values greater than 0.2 are expected).

During post-veraison, the same leaves used for SPAD measurements, were analyzed to determine the concentration of the main macro- and micronutrients $(\mathrm{N}$, $\mathrm{P}, \mathrm{K}, \mathrm{Ca}, \mathrm{Mg}, \mathrm{S}, \mathrm{Fe}, \mathrm{B}, \mathrm{Mn}, \mathrm{Cu}$ and $\mathrm{Zn}$ ). During the 2018 harvest, the quantitative production parameters (number of sprouts and bunches, real fertility and production/plant) were measured on three homogeneous plants for each test and replicate. The qualitative production parameters, like soluble solids, titratable acidity, $\mathrm{pH}$, malic acid, tartaric acid, potassium, and yeast available nitrogen (YAN) were assessed using FT IR spectrophotometer (Foss Analytical. Hillerød Denmark) evaluating samples from each experimental thesis and replicate.

Data were analyzed using STATISTICA statistical packages (version 13.0 provided by Statsoft, USA), separating the averages by Tukey test.

\section{Results and discussion}

The three-year monitoring highlights two different effects on the physio-chemical properties of soils. The first is a significant increase in the content of some nutrients $(\mathrm{P}, \mathrm{K}, \mathrm{Mg})$ in both vineyards treated with manure and with compost (to a lesser extent). The second regards the organic matter and nitrogen content: variation during the three years is negligible for both improvers under evaluation when compared to control (data not shown).

The soil biological quality index based on microarthropods (QBS-ar) and related indices, focus on the communities of arthropods (insects, myriapods, arachnids) present in the soil due to their crucial role in the recycling of nutrients. In this experiment, the qualitative and cenotic profiles were mostly not statistically different across the blocks. Only the $\mathrm{H}$ index was found to be significant, the $\mathrm{J}$ index and the Cenosis tend to be (fig. 1). The scores suggest an ongoing differentiation for the manure blocks.

It should also be noted that the manure blocks are the only one that reported median QBS-ar values higher than both the qualitative reference threshold indicated for generic soils and the reference threshold indicated in the literature for the vineyard [7].

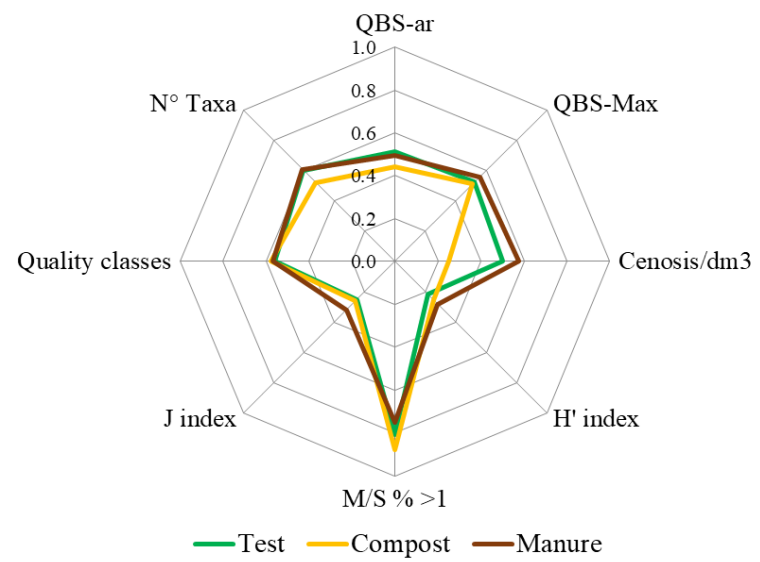

Fig. 1. Biological quality of the soil expressed with comparative diagnostics between average values of the blocks and ideal values $(=1)$ 
The data of the physico-chemical analyses of soils were found to be consistent with the three-year results of the leaf analysis. The multivariate analysis of variance (MANOVA) showed a significant year-effect for $\mathrm{N}, \mathrm{K}$, $\mathrm{Ca}, \mathrm{B}, \mathrm{Zn}$, and $\mathrm{Fe}$.

While $\mathrm{K}, \mathrm{Ca}, \mathrm{B}, \mathrm{Zn}$ decreased during the monitoring years, $\mathrm{N}$ and $\mathrm{Fe}$ increased gradually reaching the greatest content in 2017.

The treatment effects on the foliar composition were significant (tab. 3). P, K and Fe were found to increase not only in the leaves but in the soil as well. The $\mathrm{Mg}$ content, which increased in soil, was found to be decreased in the leaves. We speculated that poor absorption, probably due to the $\mathrm{K} / \mathrm{Mg}$ balances, triggered by the rainfall could have been the cause.

Table 3. Three-year foliar diagnosis: nutritional elements influenced by soil improvers (non-statistically significant data not shown)

\begin{tabular}{|c|c|c|c|c|}
\hline & $\begin{array}{c}\mathbf{P} \\
(\% \text { s.s. })\end{array}$ & $\begin{array}{c}\text { K } \\
(\% \text { s.s. })\end{array}$ & $\begin{array}{c}\text { Mg } \\
(\% \text { s.s. })\end{array}$ & $\begin{array}{c}\text { Fe } \\
(\mathbf{m g} / \mathbf{k g} \text { s.s. })\end{array}$ \\
\hline COMPOST & $0.179 \mathrm{~b}$ & $1.13 \mathrm{~b}$ & $0.33 \mathrm{~b}$ & $67.7 \mathrm{a}$ \\
\hline MANURE & $0.189 \mathrm{a}$ & $1.33 \mathrm{a}$ & $0.30 \mathrm{~b}$ & $66.8 \mathrm{a}$ \\
\hline CONTROL & $0.176 \mathrm{ab}$ & $0.91 \mathrm{c}$ & $0.40 \mathrm{a}$ & $63.0 \mathrm{~b}$ \\
\hline Sign. & $*$ & $* * *$ & $* * *$ & $*$ \\
\hline
\end{tabular}

The levels of significance reported and indicated with n.s., *, $* *, * * *$, represent not significant, significance for values of $\mathrm{P} \leq$ 0.05 and $\mathrm{P} \geq 0.01, \mathrm{P}<0.01$ and $\mathrm{P} \geq 0.001, \mathrm{P}<0.001$, respectively.

The NDVI and SPAD indices (fig. 2) describe greener plants with higher photosynthetically active biomass for the blocks where soil improvers were applied, in each relevant phenological phase.

As for to the productivity, in the Maso Romani vineyard, plants from the control group had a much higher yield comparing to the treatments $(3.26 \mathrm{~kg} / \mathrm{plant}$ against the 2.35 and $2.48 \mathrm{~kg} /$ plant of compost and manure blocks respectively.

In the Maso Toresella vineyard, the control group showed a higher average bunch weight (143 g against $127 \mathrm{~g} /$ bunch for the soil-improvers), but a lower number of bunches. Therefore, the productivity was considered almost the same as that of the non-treated group. Furthermore, at Maso Romani, the plants treated with manure showed significantly higher values of fertility of the buds compared to the untreated ones (1.88 against 1.66 respectively).

The musts quality obtained from Maso Romani vineyard (tab. 4) showed values of titratable acidity lower in the control groups, comparing to the treatments. The plants treated with both manure and compost showed higher content of malic acid and lower content of tartaric acid comparing to the control. The $\mathrm{K}$ content found in the musts from blocks treated with manure were significantly higher than those of the control. The musts of the blocks treated with manure from Maso Toresella vineyard showed a significant lower sugar content compared to the others. The total acidity value was higher in the musts obtained from vines cultivated with organic fertilizer compared to the control. About the manure application, the increase was higher, while in in the case of compost was lower.

Similarly to what was observed for Maso Romani, the $\mathrm{K}$ in the must was significantly lower in the control comparing to the treatmens. This confirms what was highlighted above with regards to a greater availability of $\mathrm{K}$ in the plant leaves.

The YAN in Maso Toresella vineyards significantly increased in the treatment with manure compared to the control, while that with compost showed intermediate values. These data consistently reflect the greater availability of nitrogen in the plant detected through foliar analysis, the highest levels of SPAD and photosynthetically active biomass observed when applying soil improvers.

Observing the musts quality parameters, the occurrence of a delay in maturation for the plants treated with soil improvers could be assumed. This is in agreement with the vegetative data results, and in according to recent work with compost [8].

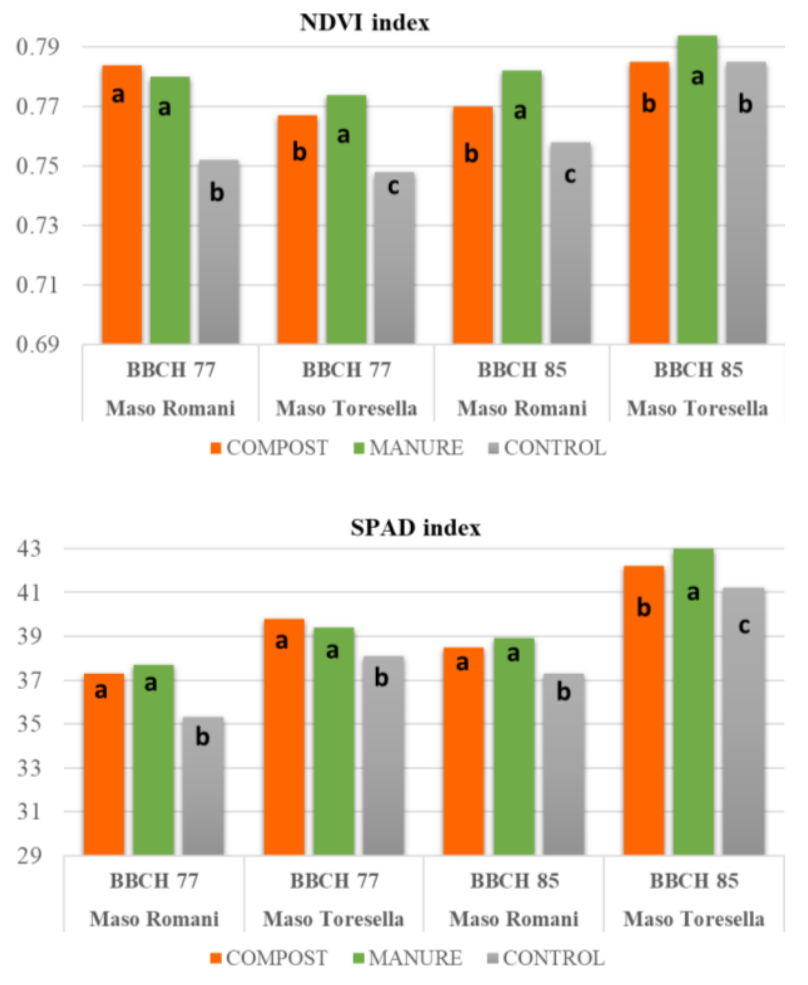

Fig. 2. Averages of three-year NDVI and SPAD indices distinct for vineyard and collection date (different letters indicate statistically significant differences for Tukey test $\mathrm{P} \leq 0.05)$ 
Table. 4. Average values of qualitative parameters of musts in relation to the blocks

\begin{tabular}{|c|c|c|c|c|}
\hline \multicolumn{5}{|c|}{ MASO ROMANI } \\
\hline & COMPOST & MANURE & CONTROL & Sign. \\
\hline${ }^{\circ}$ Brix & 20.1 & 20.0 & 20.2 & n.s. \\
\hline pH & 3.34 & 3.36 & 3.32 & n.s. \\
\hline Tit. acidity (g/L) & $5.22 \mathrm{~b}$ & $5.62 \mathrm{a}$ & $4.46 \mathrm{c}$ & $* * *$ \\
\hline Malic acid (g/L) & $2.84 \mathrm{~b}$ & $3.34 \mathrm{a}$ & $2.06 \mathrm{c}$ & $* * *$ \\
\hline Tartaric acid (g/L) & $4.44 \mathrm{~b}$ & $4.34 \mathrm{~b}$ & $4.74 \mathrm{a}$ & * \\
\hline $\mathbf{K}+(\mathbf{g} / \mathbf{L})$ & $1.47 \mathrm{ab}$ & $1.54 \mathrm{a}$ & $1.39 \mathrm{~b}$ & * \\
\hline YAN (mg/L) & 70 & 73 & 69 & n.s. \\
\hline \multicolumn{5}{|c|}{ MASO TORESELLA } \\
\hline & COMPOST & MANURE & CONTROL & Sign. \\
\hline${ }^{\circ}$ Brix & $19.9 \mathrm{a}$ & $18.6 \mathrm{~b}$ & $19.4 \mathrm{ab}$ & $*$ \\
\hline pH & $3.28 \mathrm{a}$ & $3.32 \mathrm{a}$ & $3.22 \mathrm{~b}$ & $* * *$ \\
\hline Tit. acidity (g/L) & $7.82 \mathrm{~b}$ & $8.46 \mathrm{a}$ & $7.21 \mathrm{~b}$ & $* *$ \\
\hline Malic acid (g/L) & $3.88 \mathrm{~b}$ & $4.87 \mathrm{a}$ & $3.14 \mathrm{c}$ & $* * *$ \\
\hline Tartaric acid (g/L) & $7.80 \mathrm{a}$ & $7.64 \mathrm{ab}$ & $7.51 \mathrm{~b}$ & * \\
\hline $\mathbf{K}+(\mathbf{g} / \mathbf{L})$ & $1.74 \mathrm{a}$ & $1.84 \mathrm{a}$ & $1.51 \mathrm{~b}$ & $* * *$ \\
\hline YAN (mg/L) & $308 \mathrm{ab}$ & $333 \mathrm{a}$ & $274 b$ & $*$ \\
\hline
\end{tabular}

The levels of significance reported and indicated with n.s., *,**,***, represent not significant, significance for values of $\mathrm{P} \leq 0.05$ and $\mathrm{P} \geq 0.01, \mathrm{P}<0.01$ and $\mathrm{P} \geq 0.001, \mathrm{P}$ $<0.001$, respectively

\section{Conclusion}

The application of soil improvers - especially matured manure - every three years was proven to be an effective way to provide nutrients to the vineyard and a valid alternative to mineral fertilizers.

Organic fertilization slightly increased the plants vigour while the productivity was similar to that from conventional farm fertilization. The soil improvers application determined a slight delay in maturation. The effect on the biological quality was minimal and it indicated a better ecological performance, at least for the manure-fertilised vineyards. Soil biological quality, as well as organic matter content, require longer times to highlight statistically significant variations.

\section{References}

1. Mescalchin, E. Zanzotti, R. Gobber, M. Bertoldi, D. Toniolli, F. Conte, L. L'Enologo, 5: 75-80 (2014).

2. Parisi, V. Acta naturalia de "L'Ateneo Parmense", 37, nn 3/4 (2001).

3. Parisi, V. Menta, C., Gardi, C., Jacomini, C. Agriculture, Ecosystems and Environment 105: 323-333 (2005).

4. Pielou, E.C. Journal of Theoretical Biology. 13: 131-144 (1966). doi:10.1016/00225193(66)90013-0.

5. Shannon, C. E. The Bell System Technical Journal, 27, 379-423 and 623-656 (1948).

6. Bachelier, G. Initiation-Documents Techniques $\mathrm{n}^{\circ}$ 38. O.R.S.T.O.M. Paris, 391 p. (1978).

7. Menta, C. Conti, F.D. Pinto, S., Bodini. Ecological Indicators, vol. 85: 773-780 (2018).

8. Wilson, S. G. Lambert, J. J. Dahlgren, R. American Journal of Enology and Viticulture, 72(1), 85-93 (2021). 